ВЛИЯНИЕ КОМБИНИРОВАННОГО ВВЕДЕНИЯ АГОНИСТА РЕЦЕПТОРА GPR119 С МЕТФОРМИНОМ И СИТАГЛИПТИНОМ НА УРОВЕНЬ ГЛИКЕМИИ, ВЕС ТЕЛА И ПОТРЕЕ Q ПИЩИ У ЖИВОТНЫХ, СОДЕРЖАВШИХСЯ В УСЛОВИЯХ ВЫСОКОКАЛОРИЙНОЙ И ЖИРОВОЙ ДИЕТЫ

( И.Н. Тюренков ${ }^{1 *}$, Д.В. Куркин ${ }^{1}$, Д.А. Бакулин ${ }^{1 *}$, Е.В. Волотова', Е.О. Логвинова', К.А. Авдиенко', М.А. Шафеев²

'ФГБОУ ВО «Волгоградский государственный медицинский университет» Минздрава России, Волгоград, Россия; ${ }^{2} \mathrm{AO}$ «Исследовательский институт химического разнообразия», Химки, Россия

Обоснование. Метаболический синдром и ожирение часто являются предшественниками сахарного диабета (СД) 2 типа, и современные рекомендации указывают на целесообразность раннего начала лекарственной терапии на стадии преддиабета. Средства с инкретиновой активностью являются одной из приоритетных групп при монотерапии СД 2 типа в дебюте заболевания, а отдельные препараты используются для лечения ожирения. Агонисты GPR119 повышают секрецию эндогенных инкретинов, и в настоящее время активно изучается их эффективность при лечении СД 2 типа и ожирения в моно- и комбинированной терапии.

Цель. Оценка влияния введения агониста рецептора GPR119, его комбинации с метформином или ситаглиптином на массу тела, потребление пищи и уровень гликемии у крыс в условиях высококалорийной диеты.

Материалы и методы. Исследование проведено на 56 беспородных крысах-самках возрастом 7-8 мес и начальным весом 305-320 г. Соединение ZB-16 представляет собой высокоактивный агонист рецептора GPR119 (EC50=7 нM). В течение 12 нед животные содержались на высокожировой и углеводной диете и одновременно получали соединение ZB-16, метформин и ситаглиптин либо их комбинацию (ZB-16+метформин и ZB-16+ситаглиптин). В ходе эксперимента фиксировались вес животных, масса съедаемого корма, а также уровень гликемии после 6 ч голодания и при пероральной глюкозной нагрузке.

Результаты. У животных контрольной группы, находившихся на высококалорийной и жировой диете в течение 12 нед, наблюдалось повышение массы тела, уровня гликемии и снижение скорости утилизации глюкозы. Введение агониста GPR119 (ZB-16) в течение 12 нед приводило к значимому снижению количества потребляемой пищи, ограничивало набор массы тела и предупреждало развитие нарушений углеводного обмена. Добавление ситаглиптина и особенно метформина к терапии агонистом GPR1 19 значительно повышало эффективность терапии по сравнению с контрольной группой, что выражалось в нормализации массы тела животных и уровня гликемии $(p<0,05)$.

Заключение. Введение комбинации агониста GPR119 (соединения ZB-16) с метформином и ситаглиптином более эффективно по сравнению с монотерапией ограничивает набор массы тела, потребление пищи, а также предупреждает развитие нарушений углеводного обмена у животных при содержании на высокожировой и углеводной диете.

КЛЮЧЕВЫЕ СЛОВА: GPR119; метформин; ситаглиптин; ожирение; крысы.

\title{
INFLUENCE OF NOVEL GPR119 AGONIST IN COMBINATION WITH METFORMIN AND SITAGLIPTIN ON GLYCEMIA, BODY WEIGHT AND FOOD INTAKE IN RATS FED A HIGH-FAT DIET
}

(C) Ivan N. Tyurenkov ${ }^{*}$, Denis V. Kurkin'1, Dmitry A. Bakulin, Elena V. Volotova', Ekaterina O. Logvinova', Ksenia A. Avdienko', Mikhail A. Chafeev²

'Volgograd State Medical University, Department for Pharmacology and Biopharmacy, Volgograd, Russia; ${ }^{2}$ Chemical Diversity Research Institute, Khimki, Russia

BACKGROUND: Metabolic syndrome and obesity are often precursors of type 2 diabetes mellitus (DM), and current recommendations indicate the advisability of early initiation of drug therapy at the stage of prediabetes. Drugs with incretin activity are one of the priority groups for monotherapy of type 2 diabetes in the onset of the disease, and certain drugs are used to treat obesity. GPR119 agonists increase the secretion of endogenous incretins, and their effectiveness in the treatment of type 2 diabetes and obesity in mono- and combination therapy is currently being actively studied.

AIM. To evaluate of the effect of administration of a GPR119 receptor agonist, its combination with metformin or sitagliptin on body weight, food intake and glycemia in rats under a high-calorie diet.

MATERIALS AND METHODS: The study was conducted on 56 outbred female rats aged 7-8 months and an initial weight of 305-320 g. Compound ZB-16 is a highly active GPR119 receptor agonist (EC50 = $7 \mathrm{nM})$. For 12 weeks, the animals were kept on a high-fat and carbohydrate diet and at the same time received the compound ZB-16, metformin and sitagliptin, or its combination (ZB-16 + metformin and ZB-16 + sitagliptin). During the experiment, the weight of the animals, the mass of feed eaten, as well as the level of glycemia after 6 hours of fasting and with an oral glucose load were assessed. 
RESULTS: In animals of the control group that were on a high-calorie and fatty diet for 12 weeks, an increase in body weight, glycemia and a decrease in the rate of glucose utilization were observed. The introduction of the GPR119 agonist (ZB-16) for 12 weeks led to a significant reduction in the amount of food consumed, limited weight gain and prevented the development of carbohydrate metabolism disorders. The addition of sitagliptin and especially metformin to therapy with the GPR119 agonist significantly increased the effectiveness of therapy compared to the control group, which was expressed in the normalization of animal body weight and glycemia $(p<0.05)$.

CONCLUSIONS: The introduction of a combination of the GPR119 agonist (compound ZB-16) with metformin and sitagliptin is more effective than monotherapy in terms of weight gain, food intake, and also prevents the development of carbohydrate metabolism disorders in animals when kept on a high-fat and carbohydrate diet.

KEYWORDS: GPR119; metformin; sitagliptin; obesity; rats.

\section{ОБОСНОВАНИЕ}

Высокая распространенность сахарного диабета (СД) 2 типа у лиц с избыточной массой тела [1, 2] делает актуальной задачей поиск новых терапевтических подходов к лечению нарушений углеводного обмена. При этом ключевым требованием для современных препаратов и их комбинаций является не только безопасное снижение уровня гликемии, но и уменьшение массы тела.

Среди гипогликемических препаратов доказанной способностью снижать вес тела обладают агонисты рецепторов глюкагоноподобного пептида-1 (аГПП-1Р) и ингибиторы натрий-глюкозного котранспортера 2 типа (иНГЛТ-2). В то же время остальные препараты либо не влияют (метформин, ингибиторы дипептидилпептидазы 4 (ДПП-4), ингибиторы а-глюкозидаз), либо увеличивают массу тела (тиазолидиндионы, препараты сульфонилмочевины и инсулина) [2].

В нашей стране для лечения СД рекомендовано 9 групп гипогликемических препаратов (препараты сульфонилмочевины, меглитиниды, бигуаниды, тиазолидиндионы, ингибиторы а-глюкозидаз, аГПП-1Р, ингибиторы ДПП-4, иНГЛТ-2, препараты инсулина) и их рациональные комбинации [2]. При этом для лечения ожирения, которое наблюдается у большинства пациентов с СД 2 типа или с течением времени трансформируется в него $[1,2,3]$, возможностей фармакотерапии значительно меньше. Многие препараты для снижения веса имеют существенные ограничения к применению (сибутрамин, римонабант, лоркасерин и некоторые другие). С целью снижения веса эффективно применяется орлистат, но побочные эффекты со стороны желудочно-кишечного тракта побуждают многих прибегать к альтернативным, зачастую менее эффективным вариантам терапии. Определенное влияние на массу тела при СД 2 типа и ожирении оказывает метформин, но его эффективность у лиц с избыточной массой тела без СД и инсулинорезистентности незначительная $[4,5]$.
С появлением информации о нарушениях в инкретиновой системе при СД, средства, влияющие на систему инкретинов, начали рассматриваться в качестве препаратов, способствующих снижению массы тела. Инкретиноопосредованная терапия СД (иДПП-4 и аГПП-1Р) признается одной из самых безопасных и эффективных, а в 2014 г. препарат лираглутид, рекомендованный для лечения СД 2 типа в дозах 1,2 и 1,8 мг в сутки, получил одобрение FDA в качестве средства для лечения ожирения (в дозе 3 мг) [5, 6].

Средства, влияющие на систему инкретинов, активно применяются в составе комбинированной терапии СД. Одной из рациональных комбинаций признано сочетание ингибиторов ДПП-4 с метформином, который улучшает функциональное состояние энтероэндокринных клеток (снижает апоптоз в условиях СД), что приводит к увеличению количества секретируемых инкретинов и повышению эффективности иДПП-4 [7].

В качестве нового подхода к воздействию на систему инкретинов рассматривается фармакологическая стимуляция секреции ГПП-1 и ГИП посредством активации рецептора GPR119 на энтероэндокринных клетках кишечника. Данный рецептор является сенсором некоторых компонентов пищи (ряд фосфолипидов и производных амидов жирных кислот). Его активация приводит к повышению секреции инкретинов, а агонисты GPR119 рассматриваются в качестве новой группы противодиабетических соединений [8].

К настоящему времени около десяти агонистов GPR119 дошли до I и II фазы клинических исследований. Эти препараты позиционируются как средства с высоким профилем безопасности, предназначенные для лечения СД 2 типа и ожирения в моно- и комбинированной терапии. При этом препаратами-кандидатами для создания рациональных комбинаций с агонистами GPR119 рассматриваются метформин [9] и ингибиторы ДПП-4 [10].

Химиками $3 \mathrm{AO}$ «Исследовательский институт химического разнообразия» (ЗАО «ИИХР») совместно с фармакологами Волгоградского государственного медицинского университета было создано соединение ZB-16 (рис. 1),

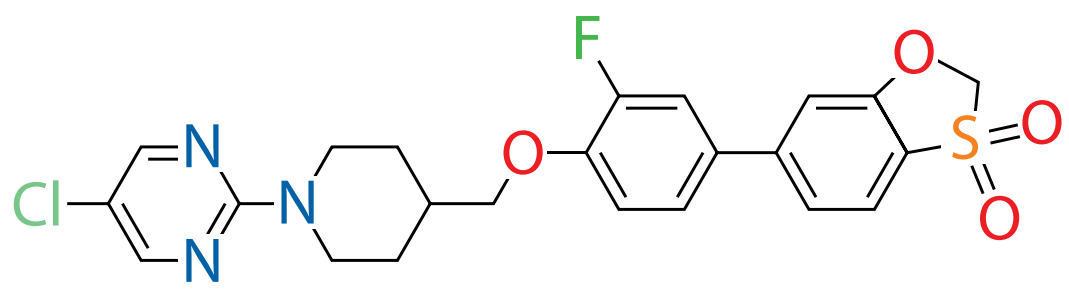

Рисунок 1. Химическая структура ZB-16. 
проявляющее высокую активность в отношении рецептора GPR119 (EC50 = 7нM) [11].

B проведенных исследованиях соединение ZB-16 в монотерапии на модели экспериментального СД проявляло гипогликемическую активность [12], а в условиях высококалорийной диеты способствовало снижению массы тела [13].

Поскольку для достижения эффективного контроля гликемии, в том числе при ожирении, активно используются комбинации гипогликемических препаратов, в настоящем исследовании была произведена оценка эффективности агониста GPR119 в комбинации с другими гипогликемическими лекарственными препаратами.

\section{ЦЕЛЬ}

Оценка влияния введения агониста рецептора GPR119, его комбинации с метформином или ситаглиптином на массу тела, потребление пищи и уровень гликемии у крыс в условиях высококалорийной диеты

\section{МЕТОДЫ}

В исследовании использовались беспородные крысы-самки, 56 особей возрастом 7-8 мес и массой 305-320 г (ФГУП «Питомник лабораторных животных «РАППОЛОВО», Ленинградская обл., Россия), которые содержались в полипропиленовых клетках (1612 см², тип: Т/4В, ООО «МЭСТ», г. Москва) по 4 особи в каждой. Дизайн исследования был одобрен Региональным независимым этическим комитетом (ГБУ «Волгоградский медицинский научный центр»): протокол № 191-2014 от 25 февраля 2014.

В течение 3 мес крысы содержались в условиях высококалорийной диеты, т.е. имели постоянный доступ к следующим продуктам: сливочное масло (на 100 г: 748 ккал; Б: 0,5 г; Ж: 82,5 г; У: 0,8 г), подсолнечная халва (на 100 г: 523 ккал; Б: 11,6 г; Ж: 29,7 г; У: 54 г) и подсолнечный козинак (на 100 г: 576 ккал, Б: 14,8 г; Ж: 42,6 г; У: 34,5 г), при этом в качестве питьевой воды животные получали раствор фруктозы (10\%) [14]. Уровень гликемии у животных определяли после 6-часовой пищевой депривации, на время которой раствор фруктозы заменяли очищенной водой.

В качестве препаратов сравнения и для комбинированного введения были выбраны препараты метформин (бигуаниды) и ситаглиптин (ингибиторы ДПП-4). Согласно клиническим рекомендациям по лечению СД (от 2017 г.), гипогликемическим препаратам данных групп отдается приоритет при монотерапии СД 2 типа в дебюте заболевания и для комбинированной терапии. Также метформин рекомендован для пациентов с сопутствующим ожирением [2], а ингибиторы ДПП-4 способствуют повышению эффективности агонистов GPR119, замедляя разрушение инкретинов [10].

Введение ZB-16, препаратов сравнения и их комбинаций осуществлялось в течение 12 нед (в утренние часы) сразу после перевода животных на высокожировую и углеводную диету. Было сформировано 7 групп по 8 животных в каждой $(\mathrm{n}=8)$.
1. Интакт (гранулированный корм ГОСТ Р51849-2001, ООО «Лабораторкорм», Москва) (интактная группа).

2. Диета + очищенная вода (0,5 мл/100 г) (контрольная группа).

3. Диета + ZB-16 (1 мг/кг).

4. Диета + метформин (400 мг/кг).

5. Диета + ZB-16 (1 мг/кг) + метформин (400 мг/кг).

6. Диета + ситаглиптин (10 мг/кг).

7. Диета + ZB-16 (1 мг/кг) + ситаглиптин (10 мг/кг).

Соединение ZB-16, препараты сравнения и их комбинации вводились животным перорально через зонд. Исследуемое соединение использовалось в наиболее активной по результатам предыдущих исследований дозе (1 мг/кг), а дозы препаратов сравнения подбирались по данным литературы $[15,16]$.

Сформированные группы соответствовали друг другу по исходному среднему весу животных, который фиксировали до диеты, через 4, 6, 8, 10 и 12 нед после изменения рациона. Потребление пищи оценивали на 12-й неделе диеты с использованием метаболических камер (3701M081, Tecniplast, Бугуджате, Италия). Концентрацию глюкозы в крови определяли на 8-й и 12-й неделе диеты. Скорость утилизации глюкозы оценивали на 12-й неделе с использованием перорального теста на толерантность к глюкозе (ПТТГ) (3 г/кг, per os). Уровень гликемии измеряли глюкометром (Bayer, Германия). Кровь забирали из подъязычной вены.

При статистической обработке данных использовали следующие критерии: One-Way ANOVA и t-критерий Стьюдента с поправкой Бонферрони (параметрические данные) либо критерий Краскела-Уоллиса и критерий Данна (непараметрические данные), соответственно данные представлены в виде графиков (среднее арифметическое значение \pm стандартная ошибка среднего) либо в виде диаграмм размаха (медиана с указанием 25-го и 75-го квартилей).

\section{РЕЗУЛЬТАТЫ}

После перевода крыс с обычного рациона на высокожировую и высококалорийную диету средний вес животных контрольной группы («Диета+вода») постепенно увеличивался и через 12 нед стал выше исходного на 23\% (рис. 2, А), тогда как вес животных, получавших комбинированный корм («Интакт»), практически не менялся (+3\%). В группах, получавших агонист GPR119 (соединение ZB-16) и его комбинацию с ситаглиптином, средняя масса животных менялась незначительно (рис. 2, В). Введение препарата метформин вызывало снижение массы тела животных ниже исходных значений, несмотря на содержание их в условиях высокожировой и калорийной диеты (рис. 2, Б), при этом его комбинация с ZB-16 была эффективней. Так, введение метформина привело к снижению массы тела в среднем на 3\%, а его комбинации с ZB-16 - на 10\%. Ситаглиптин незначительно ограничивал увеличение массы тела животных (за 12 нед увеличилась на 12\%), но снижение средней массы относительно группы «Диета+вода» не было статистически значимым $(p=0,9)$.

На завершающем этапе исследования животные всех экспериментальных групп были помещены на 3 дня в метаболические камеры с индивидуальными кормушками 
A

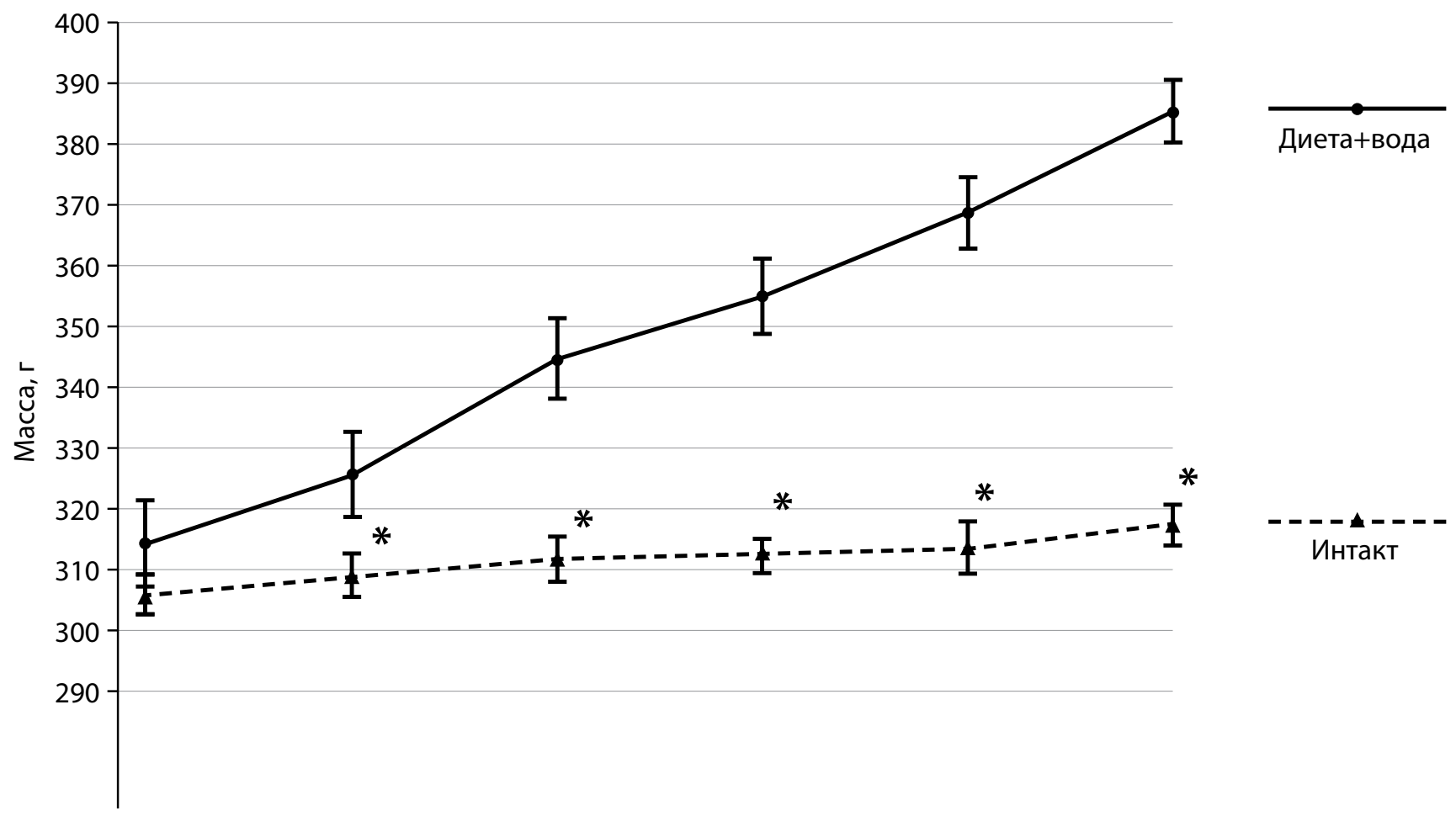

Начальные 4 недели 6 недель 8 недель 10 недель 12 недель
значения

$\mathbf{5}$

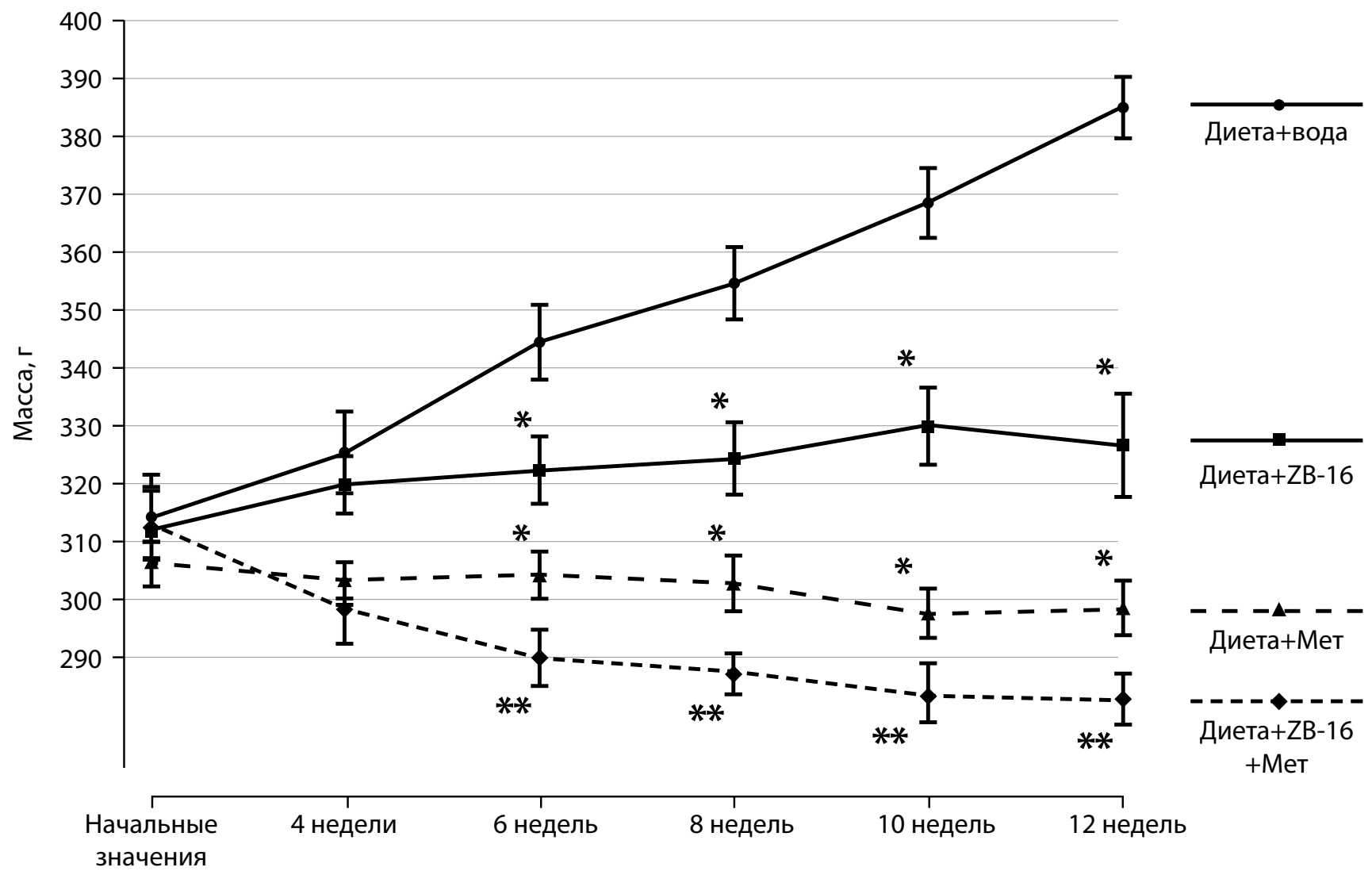

Рисунок 2. Масса животных, содержавшихся в течение 12 недель в условиях высококалорийной и жировой диеты и получавших питьевую воду (А) и ZB-16 с метформином (Б).

Примечание: *, ** - различия достоверны по отношению к группе «Диета+вода» при $p<0,05$ и p <0,01 соответственно. 
B

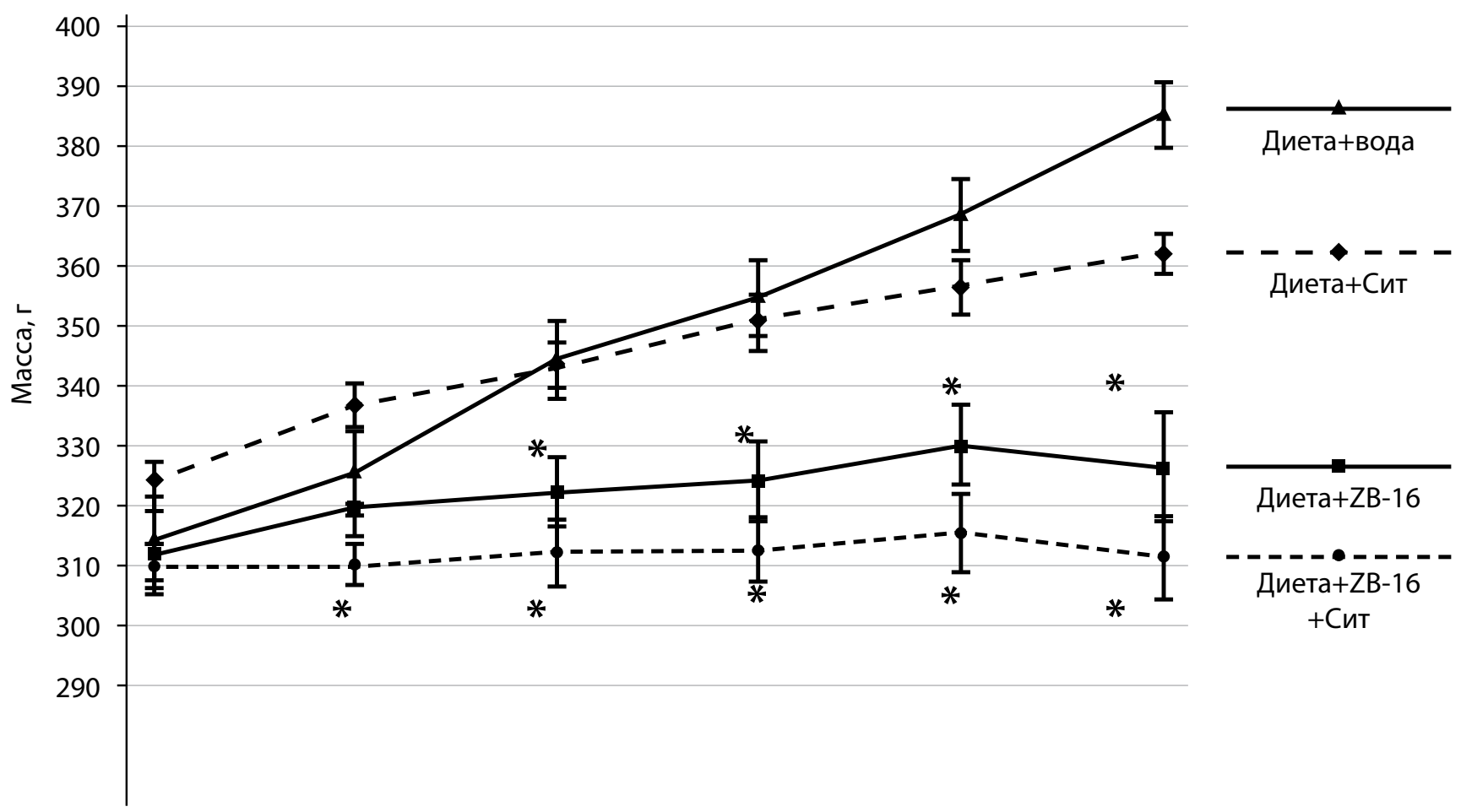

Начальные $\quad 4$ недели $\quad 6$ недель 8 недель 10 недель 12 недель
значения

Г

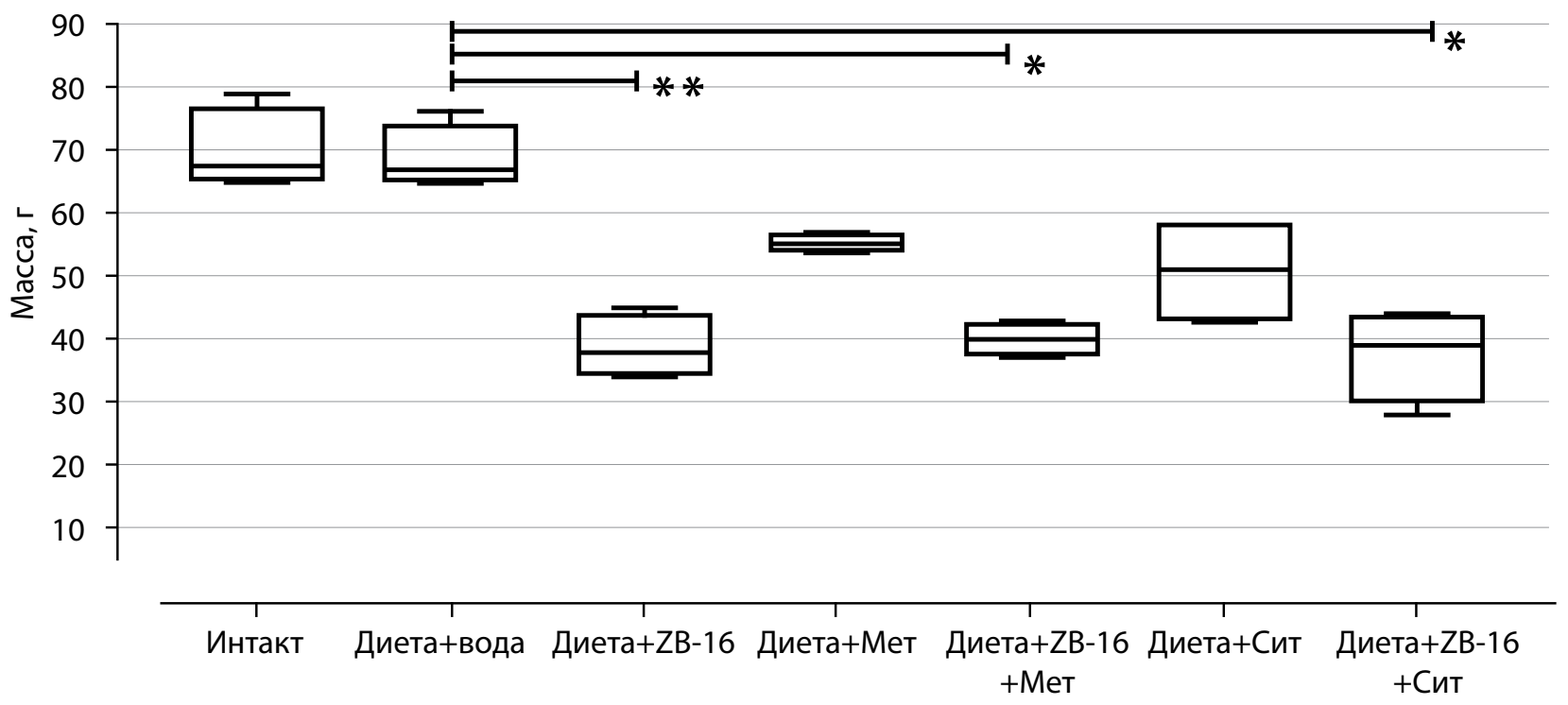

Рисунок 2 (продолжение). Масса животных, содержавшихся в течение 12 недель в условиях высококалорийной и жировой диеты и получавших ZB-16 с ситаглиптином (B). Масса корма, съедаемого за 3 дня на высококалорийной и жировой диете животными, получавшими питьевую воду, ZB-16, препараты сравнения и их комбинации (Г).

Примечание: * ${ }^{* *}$ - различия достоверны по отношению к группе «Диета+вода» при р<0,05 и р<0,01 соответственно.

для определения количества потребляемой пищи. Через 3 мес диеты средняя масса съеденного корма была сопоставимой в группе «Интакт» и «Диета+вода», при этом интактные животные имели меньшую массу (более чем на 50 г) (рис. 2, Г). Таким образом, пищевое поведение животных с переводом их на другой рацион питания не изменилось, а увеличение массы тела в группе «Диета+вода», очевидно, связано с повышенным содержанием углеводов и жиров в потребляемой пище.
В группах, которые получали метформин и ситаглиптин, наблюдалось статистически незначимое снижение количества потребляемой пищи. В то же время животные, которые перорально получали агонист GPR119, а также комбинации ZB-16 с метформином и ситаглиптином потребляли меньшее количество корма по сравнению с группой «Диета+вода» $(p<0,05)$.

Через 8 и 12 нед высококалорийной и жировой диеты уровень тощаковой гликемии (измеренной после 
A

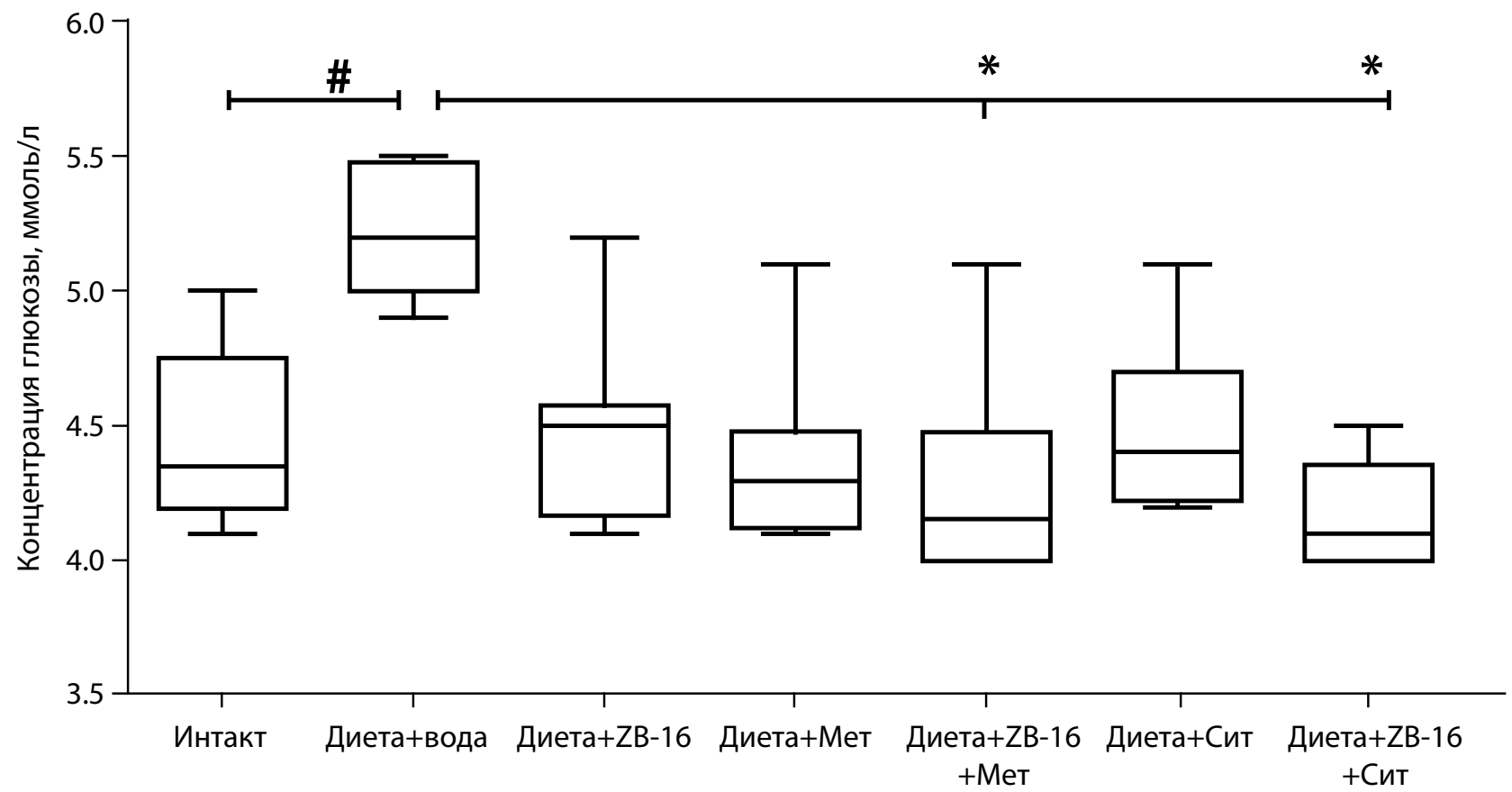

Б

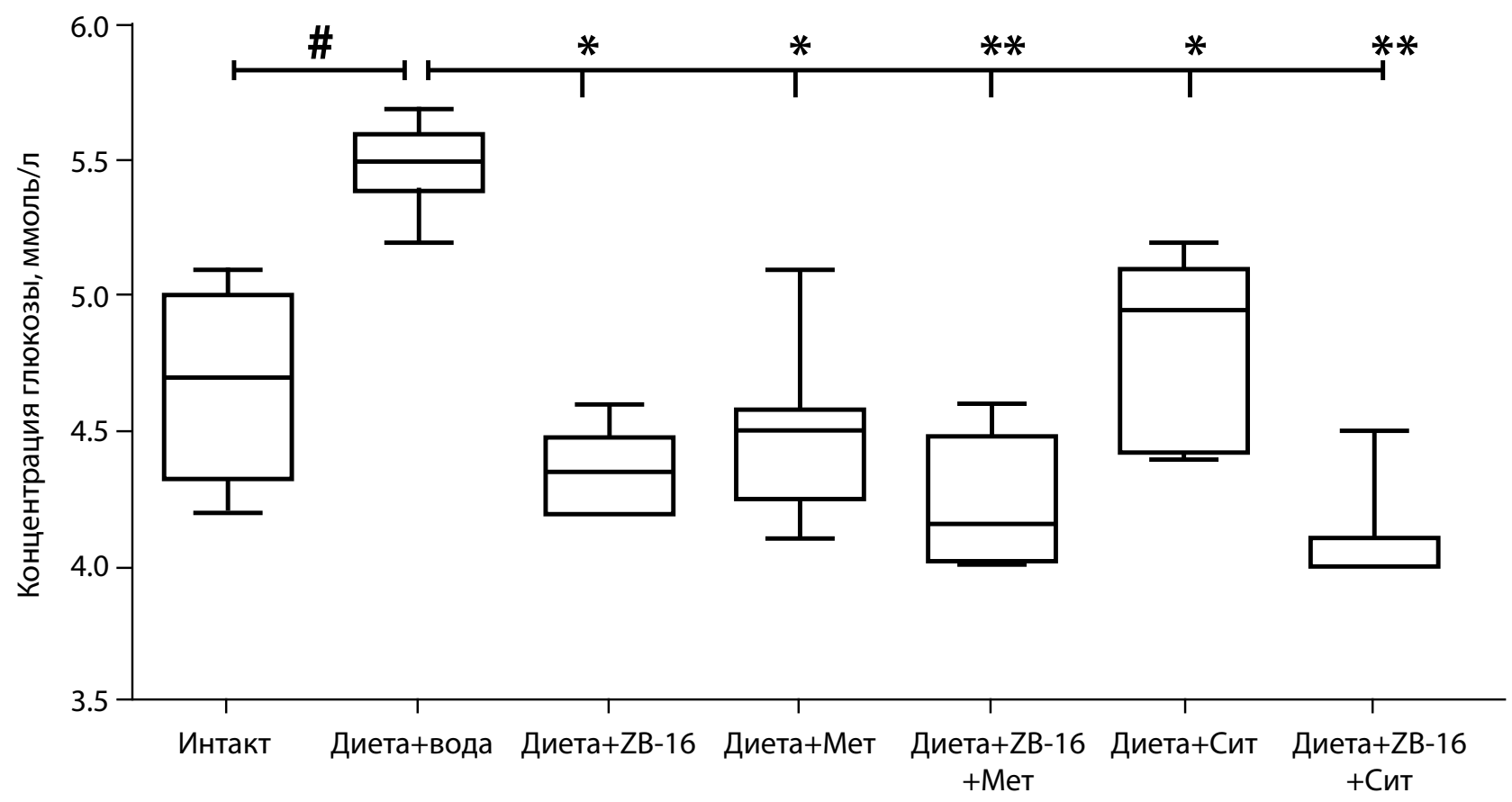

Рисунок 3. Уровень тощаковой гликемии у крыс через 8 (А) и 12 недель (Б) после начала высококалорийной и жировой диеты.

Примечание: * ** - различия достоверны по отношению к группе «Диета+вода» при p<0,05 и р<0,01 соответственно; \# - различия достоверны по отношению к группе «Интакт» при $\mathrm{p}<0,05$.

6-часового голодания) у животных без лечения был выше $(p<0,05)$, чем в интактной группе (рис. 3, A, Б). Через 8 нед диеты в группах, получавших комбинированную терапию ZB-16 с метформином или ситаглиптином, наблюдался значимо низкий уровень гликемии $(p<0,05)$ относительно группы «Диета+вода» (рис. 3, А). Спустя 12 нед более низкий уровень гликемии относительно контроля отмечался в группах, получавших как моно- $(p<0,05)$, так и комбинированную $(p<0,01)$ терапию (рис. 3, Б).
Через 12 нед диеты при проведении ПТТГ у животных контрольной группы отмечались признаки снижения скорости утилизации глюкозы, что выражалось в значительном повышении уровня гликемии через 2 ч после глюкозной нагрузки (рис. 3, В) и площади под кривой «уровень гликемии-время» (рис. 3, Г). Во всех опытных группах уровень гликемии через 2 ч после глюкозной нагрузки и значение площади под кривой были существенно ниже по сравнению с контрольной группой, при 
B

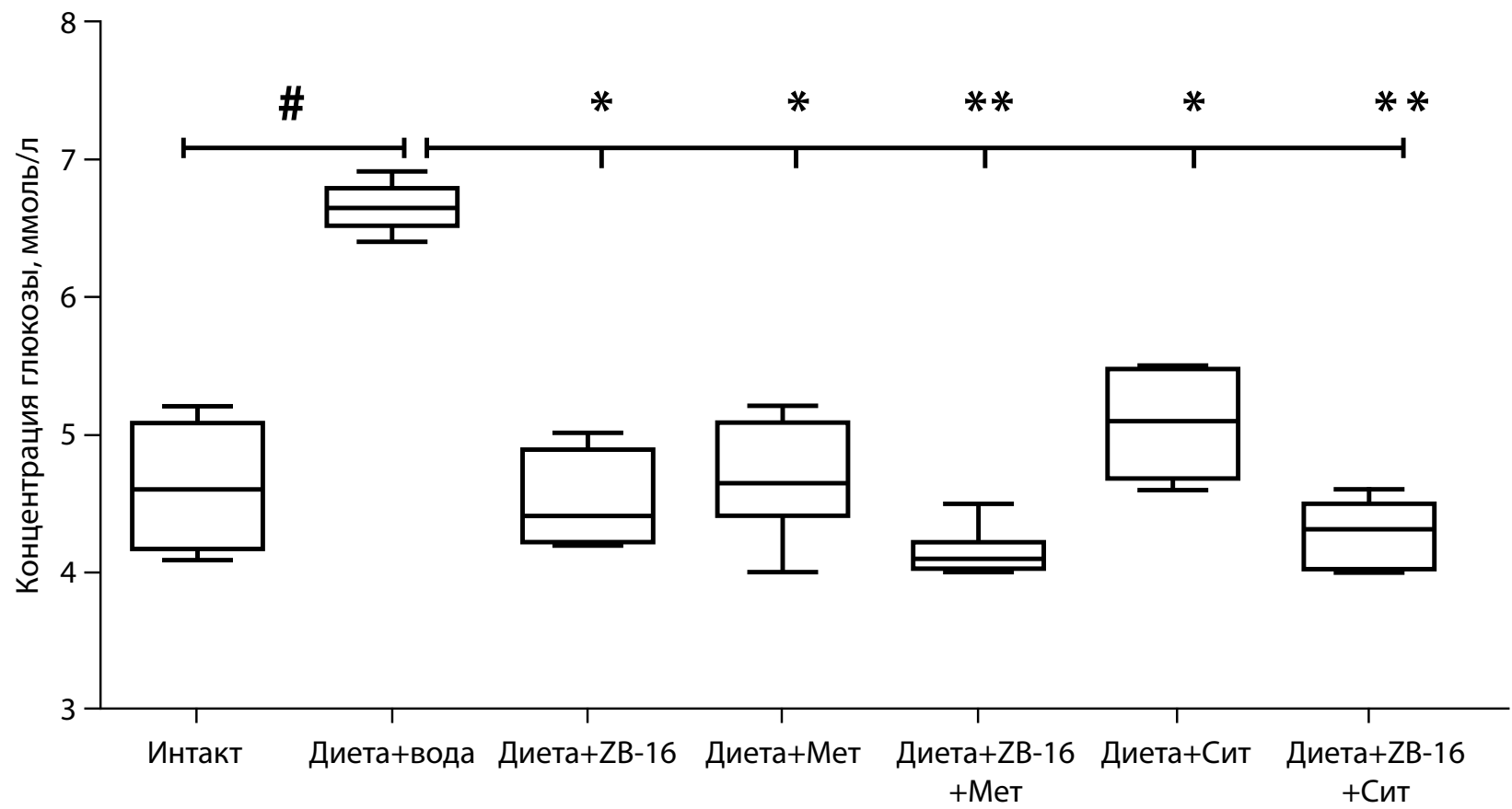

$\Gamma$

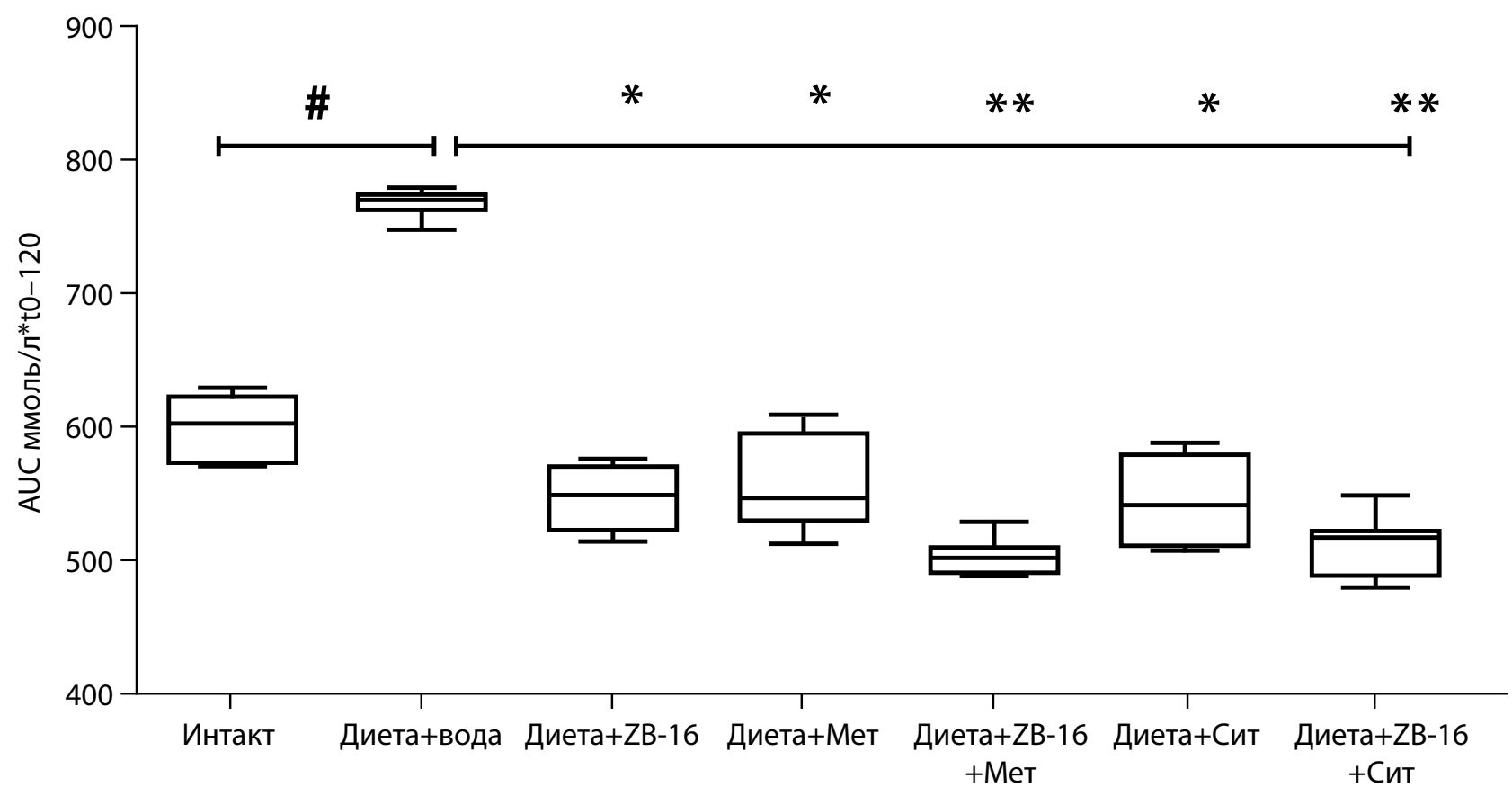

Рисунок 3 (продолжение). Уровень гликемии через 2 ч после глюкозной нагрузки (В) и площадь под кривой «уровень гликемиивремя» (Г) при проведении перорального теста на толерантность к глюкозе через 12 нед после начала диеты;

Примечание: * ** - различия достоверны по отношению к группе «Диета+вода» при $p<0,05$ и $p<0,01$ соответственно; \# - различия достоверны по отношению к группе «Интакт» при $\mathrm{p}<0,05$.

этом в группах, получавших комбинированную терапию, наблюдалось наиболее выраженное снижение $(p<0,01)$ (рис. 3, В, Г). Снижение скорости утилизации глюкозы и увеличение ее концентрации после 6-часового голодания свидетельствуют о начале формирования инсулинорезистентности, что не отмечалось у животных, получавших лечение.

\section{ОБСУЖДЕНИЕ}

Способность снижать массу тела в экспериментальных исследованиях отмечена для некоторых агонистов
GPR119 (PSN632408, PSN821 и GSK2041706), которые уменьшали массу тела подопытных животных, в том числе и за счет наличия гипофагического эффекта [17]. Комбинированное введение одного из агонистов GPR119 и метформина при терапии ожирения в эксперименте значительно повышало эффективность препаратов [9].

Влияние средств с инкретиновой активностью на потребление пищи обусловлено наличием физиологической роли ГПП-1 в функционировании оси «головной мозг - кишечник». Он регулирует аппетит посредством замедления опустошения желудка, связанного с угнетением блуждающего нерва, и формирования чувства на- 
сыщения через взаимодействие с рецептором к ГПП-1 в ядрах гипоталамуса [18]. Таким образом, влияние агонистов GPR119 на пищевое поведение и гомеостаз глюкозы может иметь инкретинопосредованную природу, хотя некоторые исследователи указывают на наличие у агонистов GPR119 независимых от инкретинов метаболических эффектов [19].

Противодиабетические свойства ZB-16 связаны со значительным влиянием на систему инкретинов, поскольку ранее установлено, что ZB-16 более чем в 2 раза увеличивало базальную и стимулированную введением глюкозы (per os) секрецию ГПП-1, что сопровождалось повышением концентрации инсулина и снижением уровня глюкозы в крови у животных с экспериментальным СД [20].

В предыдущем исследовании с использованием высококалорийной и жировой диеты соединение ZB-16 вводили в течение 4 нед после моделирования ожирения (12 нед). Введение агониста GPR119 приводило к снижению массы тела и незначительному снижению количества потребляемой пищи [13]. В представленном исследовании лечение начиналось одновременно с началом диеты, и в данной работе, помимо повышения эффективности комбинированной терапии (с метформином и ситаглиптином), отмечено выраженное влияние агониста GPR119 на потребление пищи, которое было сопоставимо во всех группах, получавших ZB-16. Повышение эффективности агониста GPR119 (в регуляции потребления пищи) при введении одновременно с началом диеты соответствует современным представлениям о целесообразности раннего начала лечения нарушений углеводного обмена.

Введение метформина также приводило к ограничению набора массы тела и снижению объема съеденного корма (за три дня). Однако масса тела на протяжении всего эксперимента у животных, получавших метформин, была меньше, чем у тех, которые получали ZB-16, а количество съедаемого животными корма было больше. Это указывает на то, что метформин в меньшей степени влияет на пищевое поведение животных, а масса тела снижается не за счет уменьшения потребления пищи, а возможно, путем снижения концентрации инсулина и инсулинорезистентности, продукции глюкозы печенью, интенсивности процессов липогенеза или благодаря другим механизмам. Совместное применение метформина и ZB-16 приводило к более выраженному ограничению набора массы, что, очевидно, связано не только с влиянием на потребление пищи животными, но и с эффектами, свойственными метформину.

\section{ЗАКЛЮЧЕНИЕ}

Замена нормального пищевого рациона на диету с высоким содержанием жиров и углеводов приводит к значительной прибавке веса и нарушению утилизации глюкозы у экспериментальных животных. Введение агониста GPR1 19 (ZB-16), метформина, ситаглиптина и их комбинаций, при содержании в условиях высококалорийной и жировой диеты, приводит к снижению потребления пищи, ограничению набора веса животными, нормализации параметров углеводного обмена. Агонист GPR119 значимо снижает потребление пищи, а добавление к ZB-16 метформина и ситаглиптина не приводит к более выраженному снижению количества потребляемого корма, однако комбинированное введение вызывает более значимое снижение массы тела и повышение скорости утилизации глюкозы по сравнению с контрольной группой в условиях высококалорийной и жировой диеты.

\section{ДОПОЛНИТЕЛЬНАЯ ИНФОРМАЦИЯ}

Источник финансирования. Работа выполнена при финансовой поддержке Министерства промышленности и торговли Российской Федерации, в рамках реализации государственного контракта «Доклинические исследования лекарственного средства для лечения сахарного диабета 2 типа на основе агонистов GPR119» № 13411.1008799 .154 от 24 июля 2013 г.

Конфликт интересов. Авторы заявляют об отсутствии конфликтов интересов, связанных с публикацией настоящей статьи.

Участие авторов. Все авторы внесли значимый вклад в проведение исследования и подготовку статьи, прочли и одобрили финальную версию статьи перед публикацией.

\section{СПИСОК ЛИТЕРАТУРЫ | REFERENCES}

Дедов И.И., Шестакова М.В., Галстян Г.Р. Распространенность сахарного диабета 2 типа у взрослого населения России (исследование NATION) // Сахарный диабет. - 2016. - Т.19. - №2. C.104-112. [Dedov II, Shestakova MV, Galstyan GR. The prevalence of type 2 diabetes mellitus in the adult population of Russia (NATION study). Diabetes mellitus. 2016;19(2):104-112. (In Russ).] doi: https://doi.org/10.14341/DM2004116-17

2. Дедов И.И., Шестакова М.В., Майоров А.Ю., и др. Алгоритмы специализированной медицинской помощи больным сахарным диабетом / Под редакцией И.И. Дедова, М.В. Шестаковой, А.Ю Майорова. - 8-й выпуск // Сахарный диабет. - 2017. - Т. 20. - №1S - C. 1-121. [Dedov II, Shestakova MV, Mayorov AY, et al. Standards of specialized diabetes care. Edited by Dedov II, Shestakova MV, Mayorov AY. 8th edition. Diabetes mellitus. 2017;(20):1S:1-121. (In Russ).] doi: https://doi.org/10.14341/DM20171S8

3. Ткачук В.А., Воротников А.В. Молекулярные механизмы развития резистентности к инсулину // Сахарный диабет. - 2014. - Т. 17. - №2. - C. 29-40. [Tkachuk VA, Vorotnikov AV. Molecular Mechanisms of Insulin Resistance Development. Diabetes mellitus. 2014;17(2):29-40. (In Russ).] doi: https://doi.org/10.14341/DM2014229-40
4. Seifarth C, Schehler B, Schneider H. Effectiveness of Metformin on Weight Loss in Non-Diabetic Individuals with Obesity. Exp Clin Endocrinol Diabetes. 2012;121(01):27-31. doi: https://doi.org/10.1055/s-0032-1327734

5. Dong Z, Xu L, Liu H, et al. Comparative efficacy of five long-term weight loss drugs: quantitative information for medication guidelines. Obes Rev. 2017;18(12):1377-1385. doi: https://doi.org/10.1111/obr.12606

6. Тюренков И.Н., Бакулин Д.А., Куркин Д.В., Волотова Е.В. Кардиоваскулярные эффекты инкретиномиметиков и их терапевтический потенциал // Вестник Российской академии медицинских наук. - 2017. - Т. 72. - № 1. - С. 66-75. [Tiurenkov IN, Kurkin DV, Bakulin DA, Volotova EV. Cardiovascular effects of incretin-based therapies and their therapeutic potential. Annals of the Russian academy of medical sciences. 2017;72(1):66-75 (In Russ).] doi: 10.15690/vramn732

7. Bahne E, Hansen M, Brønden A, et al. Involvement of glucagon-like peptide- 1 in the glucose-lowering effect of metformin. Diabetes, Obes Metab. 2016;18(10):955-961. doi: https://doi.org/10.1111/dom.12697 
8. Ritter K, Buning C, Halland N, et al. G Protein-Coupled Receptor 119 (GPR119) Agonists for the Treatment of Diabetes: Recent Progress and Prevailing Challenges. J Med Chem. 2016;59(8):3579-3592. doi: https://doi.org/10.1021/acs.jmedchem.5b01198

9. Al-Barazanji K, McNulty J, Binz J, et al. Synergistic Effects of a GPR1 19 Agonist with Metformin on Weight Loss in DietInduced Obese Mice. J Pharmacol Exp Ther. 2015;353(3):496-504. doi: https://doi.org/10.1124/jpet.115.222828

10. Park YH, Choi HH, Lee DH, et al. YH18421, a novel GPR119 agonist exerts sustained glucose lowering and weight loss in diabetic mouse model. Arch Pharm Res. 2017;40(6):772-782. doi: https://doi.org/10.1007/s12272-017-0925-y

11. Патент РФ на изобретение №2576037/ 28.11.2014. Бюл. №6. Иващенко А.В., Иващенко А.А., Кравченко Д.В., и др. Замещенные 4-\{[4-(3,3-диоксидо-1,3-бензоксатиол-6-ил)арилокси] метил\} пиперидины как агонисты рецепторов GPR119, фармацевтическая композиция, способы их получения и применения. [Patent RUS №2576037/ 28.11.2014. Byul. №6. Ivashchenko AV, Ivashchenko AA, Kravchenko DV., et al. Substituted 4-\{[4-(3,3-dioxido-1,3-benzoxathiol-6-yl)aryloxy]methyl\}piperidines as GPR119 receptor agonists, pharmaceutical composition, methods for producing and using them. (In Russ).] Доступно по: http://www.findpatent.ru/patent/257/2576037.html. Ссылка активна на 20.11.2019

12. Тюренков И.Н., Куркин Д.В., Бакулин Д.А., и др. Сравнение гипогликемической активности нового агониста GPR119 и ингибитора ДПП-4 ситаглиптина // Проблемы Эндокринологии. - 2016. - T. 62. - №1. - C. 38-43. [Tyurenkov IN, Kurkin DV, Bakulin DA, et al. Comparing hypoglycemic activity of novel GPR119 agonist and DPP-4 inhibitor sitagliptin. Problems of Endocrinology. 2016;62(1):38-43. (In Russ).] doi: https://doi.org/10.14341/probl201662138-43

13. Тюренков И.Н., Куркин Д.В., Бакулин Д.А. и др. Влияние агониста рецептора GPR119 на уровень глюкозы, массу тела и потребление пищи у животных с ожирением, обусловленным высокожировой и углеводной диетой // Проблемы эндокринологии. - 2016. - Т. 62. - №1. - С. 44-49. [Tiurenkov IN, Kurkin DV, Bakulin DA, et al. The influence of novel
GPR119 agonist on body weight, food intake and glucose metabolism in obesity rats provoked high-fat and-carbohydrate diet. Problems of Endocrinology. 2016:62(1):44-49. (In Russ).] doi: https://doi.org/10.14341/probl201662144-49

14. Решетняк М.В., Хирмаков В.Н., Зыбина Н.Н., и др. Модель метаболического синдрома, вызванного кормлением фруктозой: патологические взаимосвязи обменных нарушений. // Медицинский академический журнал. - 2011. - Т.11. - №3. C. 23-27. [Reshetnyak MV, Khirmanov VN, Zybina NN, et al. Fructosefed model of the metabolic syndrome: pathogenetic relationships between metabolic disorders. Meditsinskii akademicheskii zhurnal. 2011;11(3):23-27. (In Russ).

15. Ismail TA, Soliman MM, Nassan MA. Molecular and immunohistochemical effects of metformin in a rat model of type 2 diabetes mellitus. Exp Ther Med. 2015;9(5):1921-1930. doi: https://doi.org/10.3892/etm.2015.2354

16. Poucher SM, Cheetham S, Francis J, et al. Effects of saxagliptin and sitagliptin on glycaemic control and pancreatic $\beta$-cell mass in a streptozotocin-induced mouse model of type 2 diabetes. Diabetes, Obes Metab. 2012;14(10):918-926. doi: https://doi.org/10.1111/j.1463-1326.2012.01619.x

17. Shah U, Edmondson S, Szewczyk JW. Chapter 7. Recent Advances in the Discovery of GPR119 Agonists. In: Jones RM, ed. New Therapeutic Strategies for Type 2 Diabetes. Cambridge: Royal Society of Chemistry; 2012. p.:177-214. doi: https://doi.org/10.1039/9781849735322-00177

18. Cabou C, Burcelin R. GLP-1, the Gut-Brain, and BrainPeriphery Axes. Rev Diabet Stud. 2011;8(3):418-431. doi: https://doi.org/10.1900/RDS.2011.8.418

19. Flock G, Holland D, Seino Y, Drucker DJ. GPR1 19 Regulates Murine Glucose Homeostasis Through Incretin Receptor-Dependent and Independent Mechanisms. Endocrinology. 2011;152(2):374-383. doi: https://doi.org/10.1210/en.2010-1047

20. Tyurenkov IN, Kurkin DV., Bakulin DA, et al. ZB-16, a Novel GPR1 19 Agonist, Relieves the Severity of Streptozotocin-Nicotinamide-Induced Diabetes in Rats. Front Endocrinol (Lausanne). 2017;8(2):374-383. doi: https://doi.org/10.3389/fendo.2017.00152

\section{ИНФОРМАЦИЯ ОБ АВТОРАХ [AUTHORS INFO]:}

*Бакулин Дмитрий Александрович, к.м.н. [Dmitry A. Bakulin, PhD]; адрес: Россия, 400001, Волгоград, ул. Пугачевская, д. 3 [address: 3 Pugachevskaja street, 400001, Volgograd, Russia];

ORCID: http://orcid.org/0000-0003-4694-3066; eLibrary SPIN: 3339-7228; e-mail: mbfdoc@gmail.com

Тюренков Иван Николаевич, д.м.н., профессор, член-корр. PAH [lvan N. Tyurenkov, MD, PhD, Professor]; ORCID: http://orcid.org/0000-0001-7574-3923; eLibrary SPIN: 6195-6378; e-mail: fibfuv@mail.ru

Куркин Денис Владимирович, к.фарм.н. [Denis V. Kurkin, PhD in pharmacy]; ORCID: http://orcid.org/0000-0002-1116-3425; eLibrary SPIN: 8771-1461; e-mail: strannik986@mail.ru

Волотова Елена Владимировна, д.м.н. [Eelena V. Volotova, PhD]; ORCID: http://orcid.org/0000-0003-3916-7249; eLibrary SPIN: 1483-0915; e-mail: ev.volotova@gmail.com

Логвинова Екатерина Олеговна [Ekaterina O. Logvinova]; eLibrary SPIN: 9911-9257; e-mail: life-d@mail.ru Авдиенко Ксения Андреевна, студент [Kseniia A. Avdienko, student]; e-mail: avdienko.ksenya@mail.ru Шафеев Михаил Айратович, к.X.H. [Mihail A. Shafeev, PhD in chemistry]; e-mail: chafeev@inbox.ru

*Авторы, ответственные за переписку.

\section{ЦИТИРОВАТЬ:}

Тюренков И.Н., Куркин Д.В., Бакулин Д.А., Волотова Е.В., Логвинова Е.О., Авдиенко К.А., Шафеев М.А. Влияние комбинированного введения агониста рецептора GPR119 с метформином и ситаглиптином на уровень гликемии вес тела и потребление пищи у животных, содержавшихся в условиях высококалорийной и жировой диеты // Ожирение и метаболизм. — 2019. - Т.16. — №3. - C.46-54. doi: https://doi.org/10.14341/omet9422

\section{TO CITE THIS ARTICLE:}

Tyurenkov IN, Kurkin DV, Bakulin DA, Volotova EV, Logvinova EO, Avdienko KA, Chafeev MA. Influence of novel GPR119 agonist in combination with metformin and sitagliptin on glycemia, body weight and food intake in rats fed a high-fat diet. Obesity and metabolism. 2019;16(3):46-54. doi: https://doi.org/10.14341/omet9422 